\title{
The effect of demographic features on aortic arch anatomy and its role in the etiology of cerebrovascular disease
}

This article was published in the following Dove Press journal:

Neuropsychiatric Disease and Treatment

\author{
Yılmaz İnanç' \\ Yusuf İnanç ${ }^{2}$ \\ Halil $\mathrm{Ay}^{3}$ \\ 'Department of Neurology, Faculty \\ of Medicine, Kahramanmaraș Sutcu \\ Imam University, Kahramanmaraș, \\ ${ }^{2}$ Department of Neurology, Faculty \\ of Medicine, Gaziantep University, \\ Gaziantep, ${ }^{3}$ Department of Neurology, \\ Faculty of Medicine, Harran \\ University, Harran, Turkey
}

Purpose: The aim of this study was to retrospectively evaluate the distribution of aortic arches, the relationship with demographic characteristics, and the results of carotid and vertebral artery stenting procedures in patients diagnosed with cerebrovascular disease through the intra-arterial digital subtraction angiography (DSA) technique.

Methods: A retrospective examination was performed on 288 patients diagnosed with cerebrovascular disease, who underwent DSA in the Department of Neurology of Gaziantep University Medical Faculty and Kahramanmaraş Sütçü Imam University Medical Faculty. The patients were examined in respect of demographic features and aortic arch anatomic structure characteristics. All demographic characteristics, DSA, carotid, and vertebral artery stent results were recorded. Results: The patients comprised $60.1 \%$ males and $39.9 \%$ females with a mean age of 58.25 years. Type 2 aortic arch was found in 175 (60.7\%) patients, Type 2 aortic arch in 99 (34.3\%) patients, and Type 3 aortic arch in $14(4.8 \%)$ patients. The right carotid artery stenosis rate was found to be higher in patients with Type 2 aortic arch $(P=0.013)$. When the patients were evaluated according to the presence of a bovine arch, there was no significant difference in terms of age, carotid, and vertebral artery lesions $(P>0.05)$.

Conclusion: The aortic arch and its branching properties were not found to have a direct effect on increased risk of cerebrovascular disease or stenting rates. This study can be considered to raise awareness for new studies to demonstrate the effect of aortic arch anatomic differences on cerebrovascular diseases.

Keywords: aortic arch, stroke, bovine arch, aorta, invasive neurology

\section{Introduction}

Stroke is the third most common cause of death worldwide. ${ }^{1}$ In one of three stroke patients, atherosclerotic lesions of the aortic arch branches and carotid arteries are held responsible. ${ }^{2,3}$ The final shape of the aortic arch and its branches is thought to be related to the possible different splitting ratios of several arterial structures and to the "migration" and "merging" characteristics, with anatomic variations ranging from $15 \%$ to $30 \%{ }^{4}$ It is known that these different anatomic features lead to secondary ischemic problems due to maneuvering difficulties and the time spent in vascular interventional treatments and surgical treatments. Therefore, the anatomic structures of the aortic arch and supra-aortic branches are of great importance for all invasive interventionists and vascular surgeons. Some variations in cerebral vessels may lead to changes in blood flow, which may be a risk for the occurrence of cerebrovascular diseases. There are few studies in which these variabilities are assessed on cerebral diseases.
Correspondence: Yılmaz İnanç Department of Neurology, Faculty of Medicine, Kahramanmaraș Sutcu Imam University, Kahramanmaraș, Turkey Tel +9050522I 0986 Email drinancc@gmail.com (c)
hereby accept the Terms. Non-commercial uses of the work are permitted without any further permission from Dove Medical Press Limited, provided the work is properly attributed. For permission hereby accept the Terms. Non-commercial uses of the work are permitted without any further permission from Dove Medic
for commercial use of this work, please see paragraphs 4.2 and 5 of our Terms (https://www.dovepress.com/terms.php). 
This study aimed to reveal the differences between the aortic arch types, atherosclerotic features, and invasive intervention needs and the demographic characteristics of hospitalized patients in our clinic who had been diagnosed with brain vascular disease and who had undergone digital subtraction angiography (DSA) for further examination.

\section{Methods}

A retrospective examination was performed on patients in the Department of Neurology of Gaziantep University Medical Faculty and Kahramanmaraş Sütçü Imam University Medical Faculty in 2015. All participants provided informed consent. All procedures performed in studies involving human participants were in accordance with the ethical standards of the Gaziantep University Medical Faculty Medical Ethical Committee who approved this study. Patients included in the study were those who had been diagnosed with cerebrovascular disease, who had undergone DSA for further examination from the full series of patients detected with severe stenosis on carotid-vertebral ultrasound, computerized tomography angiography, and magnetic resonance angiography, who had subarachnoid hemorrhage, who were assumed to have central nervous system vasculitis, and young patients who had stroke of undetermined etiology. The patients were retrospectively investigated in terms of demographic features and aortic arch anatomic structure. The assessment of aortic angles and branching was performed by an experienced interventional neurology specialist. These variables were compared with age, gender, and atherosclerotic risk factors (diabetes, hypertension, coronary artery disease, and hyperlipidemia) and demographic characteristics (education, smoking habits, and marital status).

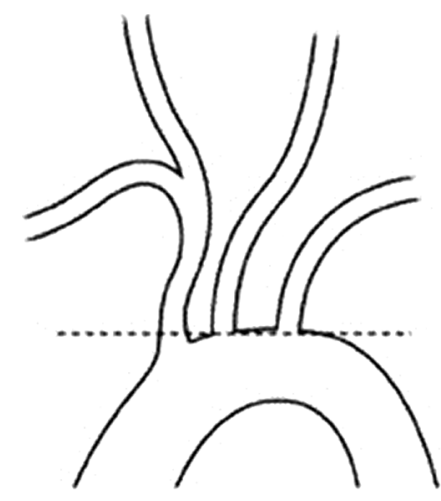

Type I

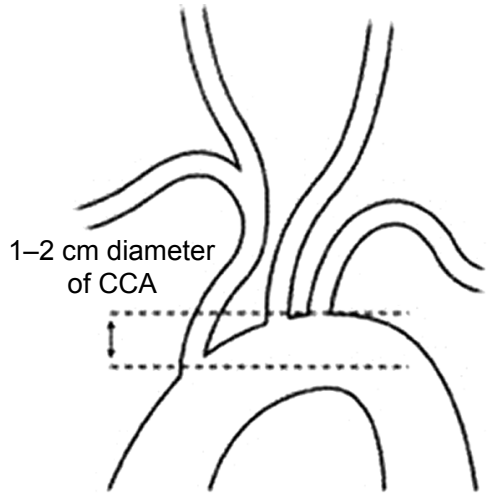

Type II

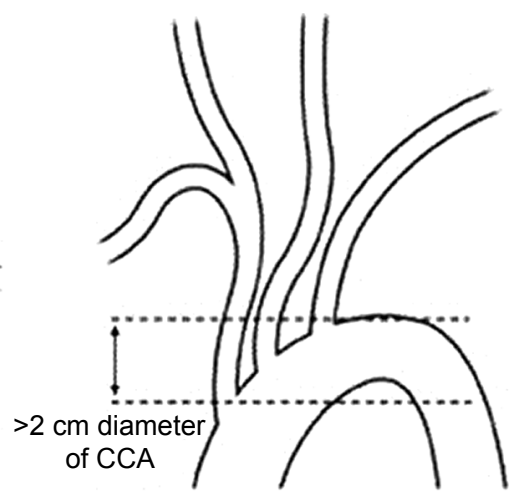

Type III

Figure I Illustration of the three types of the aortic arch. The upper line indicates the level of the top of the aortic arch, and the dotted line indicates the level of the origin of the brachiocephalic branch.

Abbreviation: CCA, common carotid artery.

\section{Intra-arterial DSA uptake}

Intra-arterial DSA uptake is a highly sensitive and specific imaging modality in the screening of congenital and acquired aortic diseases. ${ }^{5,6}$ In this study, aortic arch angiograms were obtained in the left anterior oblique position with contrast agent administered through a $5 \mathrm{Fr}$ pigtail catheter near to the skull base and scans were taken of the aortic arch and supraaortic branches. The anatomic features of the aortic arch and carotid arteries were evaluated from the angiographic images using the ImageJ software.

\section{Evaluation of the aortic arch}

The most common aortic arch branching pattern in humans is the branching pattern of three large vessels originating from the aorta. The first branch is the innominate artery, which branches into the right subclavian artery and the right main carotid artery branches. The most common second branch is the left main carotid artery. The last branch is known as the left subclavian artery.

The branching pattern of the aorta is made according to the vertical distance of the brachiocephalic branch to the apex of the aortic arch. If this distance is shorter than the diameter of one artery, it is evaluated as Type 1 aortic arch, between one and two arteries as Type 2 aortic arch, and more than two arteries as Type 3 aortic arch (Figure 1).

Bovine arch is known as the most common aortic branching variant and is assessed according to the branching slope of the brachiocephalic trunk (Figure 2). ${ }^{7,8}$

\section{Statistical methods}

The SPSS 22.0 program was used to analyze the variables. The normal distribution of the data was evaluated using the 

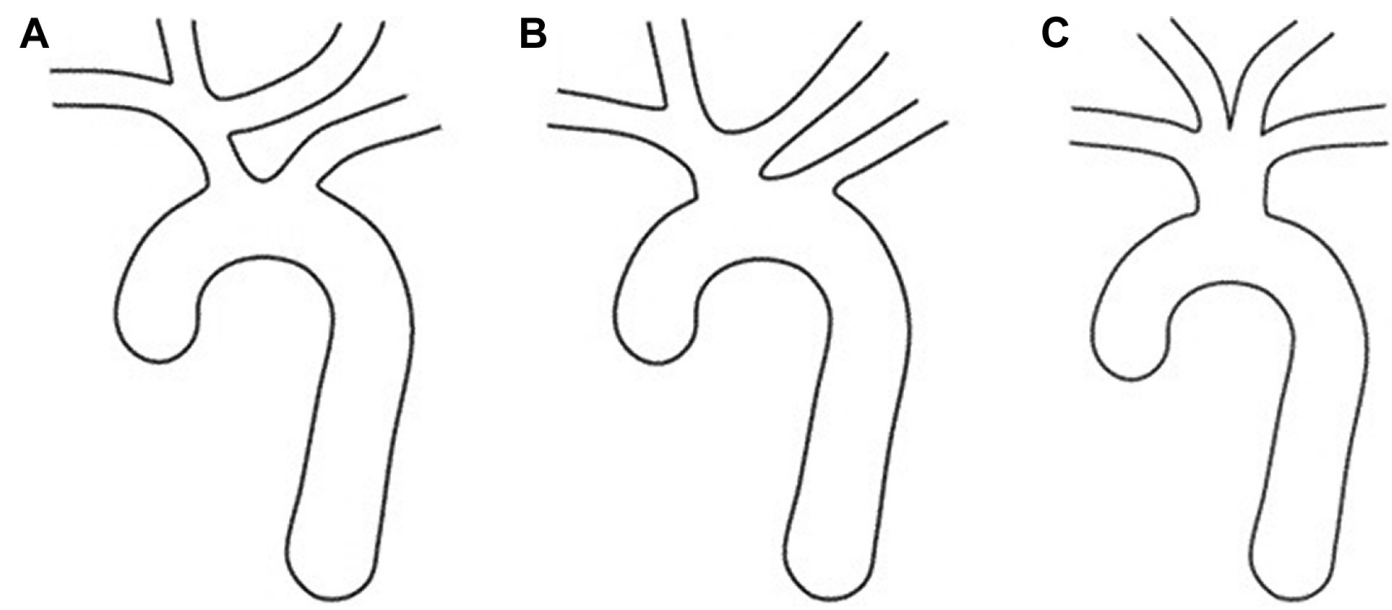

Figure 2 (A) Bovine arch - left common carotid artery originating from the innominate artery. (B) Bovine arch - common origin of the innominate artery and left common carotid artery. (C) True bovine arch.

Shapiro-Wilk test. Variance homogeneity of the data was evaluated using the Levene test. The independent samples $T$-test was used with the Bootstrap results, while the MannWhitney $U$ test was used with the Monte Carlo results. The Kruskal-Wallis $H$ test from the nonparametric tests was applied to the results of the Monte Carlo simulation technique, and one-way analysis of variance Bootstrap results from parametric methods were used to compare independent groups quantitatively. The Dunn's test was used for post hoc analyses. In the comparison of categorical variables, the Pearson's chi-squared and Fisher's exact tests and the Monte Carlo simulation technique were used. Quantitative variables were shown as mean \pm standard deviation and median range (maximum-minimum), and categorical variables were shown as number (n) and percentage (\%) in the tables. Variables were examined at $95 \%$ confidence level, and a $P$-value of $<0.05$ was considered as statistically significant.

\section{Results}

The results of the evaluations of mean age and arch types of the patients in the study are shown in Table 1 . The patients comprised $60.1 \%$ males and $39.9 \%$ females with a mean age of 58.25 years. When the patients were classified according to arch types, no statistically significant difference was found between the groups in terms of age $(P=0.108)$.

When the median values of patients grouped in terms of the aortic arch and carotid artery lesion localizations were examined, right carotid artery stenosis was found at a higher rate in patients with Type 2 aortic $\operatorname{arch}(P=0.013)$. No significant difference was found between left carotid artery,

Table I Carotid and vertebral artery lesions of the patients compared to aortic arch types

\begin{tabular}{|c|c|c|c|c|c|c|c|}
\hline & \multicolumn{3}{|l|}{ Type of arch } & \multirow[t]{3}{*}{$P$-value } & \multicolumn{3}{|c|}{$\begin{array}{l}\text { Paired comparison, } \\
P \text {-value }\end{array}$} \\
\hline & Type I & Type 2 & Type 3 & & I-II & I-III & II-III \\
\hline & Mean \pm SD & Mean \pm SD & Mean \pm SD & & & & \\
\hline \multirow[t]{2}{*}{ Age, years } & $57.31 \pm 13.99$ & $58.93 \pm 14.00$ & $65.14 \pm 11.62$ & 0.108 & NS & NS & NS \\
\hline & $\begin{array}{l}\text { Median } \\
\text { (maximum-minimum) }\end{array}$ & $\begin{array}{l}\text { Median } \\
\text { (maximum-minimum) }\end{array}$ & $\begin{array}{l}\text { Median } \\
\text { (maximum-minimum) }\end{array}$ & & & & \\
\hline $\mathrm{RCA}$ & $0(100-0)$ & $0.7(100-0)$ & $0(40-0)$ & 0.013 & 0.018 & 0.450 & 0.057 \\
\hline LCA & $0(99-0)$ & $0(100-0)$ & $0(50-0)$ & 0.056 & NS & NS & NS \\
\hline RVA & $60(100-1)$ & $40(95-30)$ & $55(60-50)$ & 0.800 & NS & NS & NS \\
\hline LVA & $40(100-20)$ & $50(100-30)$ & $40(95-30)$ & 0.823 & NS & NS & NS \\
\hline
\end{tabular}

Notes: One-way ANOVA for age, Kruskal-Wallis test (Monte Carlo); post hoc test: Dunn's test for the others.

Abbreviations: ANOVA, analysis of variance; LCA, left carotid artery; LVA, left vertebral artery; NS, nonsignificant; RCA, right carotid artery; RVA, right vertebral artery; $\mathrm{SD}$, standard deviation. 
Table 2 Carotid and vertebral artery lesions of the patients evaluated according to the presence of bovine arch

\begin{tabular}{|c|c|c|c|c|}
\hline & \multicolumn{3}{|l|}{ Bovine arch } & \multirow[t]{3}{*}{$P$-value } \\
\hline & Not availalbe & Available & Total & \\
\hline & Mean \pm SD & Mean \pm SD & Mean \pm SD & \\
\hline \multirow[t]{2}{*}{ Age, years } & $57.76 \pm 14.15$ & $60.58 \pm 12.86$ & $58.25 \pm 13.95$ & 0.185 \\
\hline & $\begin{array}{l}\text { Median } \\
\text { (maximum-minimum) }\end{array}$ & $\begin{array}{l}\text { Median } \\
\text { (maximum-minimum) }\end{array}$ & $\begin{array}{l}\text { Median } \\
\text { (maximum-minimum) }\end{array}$ & \\
\hline $\mathrm{RCA}$ & $0(100-0)$ & $0(70-0)$ & $0(100-0)$ & 0.132 \\
\hline LCA & $0(100-0)$ & $0(90-0)$ & $0(100-0)$ & 0.797 \\
\hline RVA & $60(100-1)$ & $30(70-30)$ & $50(100-1)$ & 0.144 \\
\hline LVA & $40(100-20)$ & $35(40-30)$ & $40(100-20)$ & 0.496 \\
\hline
\end{tabular}

Notes: Independent $t$-test (Bootstrap) for age; Mann-Whitney $U$ test (Monte Carlo) for the others.

Abbreviations: LCA, left carotid artery; LVA, left vertebral artery; RCA, right carotid artery; RVA, right vertebral artery; SD, standard deviation.

right vertebral artery, and left vertebral artery stenosis rates ( $P=0.056,0.800$, and 0.823 , respectively).

Patients were grouped according to the presence of bovine arch (Table 2). No significant difference was found between the patient groups in terms of age, carotid, and vertebral artery lesions $(P>0.05)$.

The demographic characteristics of the patients according to aortic arch types are summarized in Table 3. No significant difference was found between the aortic arch types of the patients in terms of chronic diseases, educational status, and marital status $(P>0.05)$. Type 1 aortic arch was found in $175(60.7 \%)$ patients, Type 2 aortic arch was found in 99 (34.3\%) patients, and Type 3 aortic arch was found in 14 (4.8\%) patients (Table 3 ).

The evaluation of carotid artery stenosis and stenting procedures according to aortic arch types of the patients is shown in Table 4 . Right carotid artery stenosis ( $\geq 50 \%$ ) and stenting rates were found to be higher than in other arteries $(P<0.022$ and 0.028 , respectively). There were no differences between the arch types in the left carotid artery and vertebral arteries $(P>0.05)$ (Table 4).

Table 3 Demographic characteristics of patients evaluated according to aortic arch types

\begin{tabular}{|c|c|c|c|c|c|}
\hline & \multicolumn{4}{|l|}{ Arch types } & \multirow[t]{2}{*}{$P$-value } \\
\hline & Type I, n (\%) & Type 2, n (\%) & Type 3, n (\%) & Total, n (\%) & \\
\hline \multicolumn{6}{|l|}{ Education } \\
\hline No & $60(34.29)$ & 37 (37.37) & $7(50)$ & $104(36.11)$ & 0.475 \\
\hline Yes & II 5 (65.7I) & $62(62.63)$ & $7(50)$ & I84 (63.89) & \\
\hline \multicolumn{6}{|c|}{ Marital status } \\
\hline Single & $70(40)$ & $4 I(4 I .4 I)$ & $7(50)$ & I I 8 (40.97) & 0.765 \\
\hline Married & $105(60)$ & 58 (58.59) & $7(50)$ & $170(59.03)$ & \\
\hline \multicolumn{6}{|l|}{ Gender } \\
\hline Male & $105(60)$ & 61 (6I.62) & $7(50)$ & $173(60.07)$ & 0.716 \\
\hline Female & $70(40)$ & $38(38.38)$ & $7(50)$ & 115 (39.93) & \\
\hline \multicolumn{6}{|l|}{ Smoking } \\
\hline No & $140(80)$ & 73 (73.74) & $13(92.86)$ & $226(78.47)$ & 0.224 \\
\hline Yes & $35(20)$ & $26(26.26)$ & I (7.I4) & $62(21.53)$ & \\
\hline \multicolumn{6}{|l|}{ HT } \\
\hline No & 108 (62.07) & 61 (6I.62) & $8(57.14)$ & 177 (6I.67) & 0.929 \\
\hline Yes & $66(37.93)$ & 38 (38.38) & $6(42.86)$ & $110(38.33)$ & \\
\hline \multicolumn{6}{|l|}{ DM } \\
\hline No & I 34 (76.57) & 7I (7I.72) & $10(71.43)$ & $215(74.65)$ & 0.652 \\
\hline Yes & $4 \mathrm{I}(23.43)$ & $28(28.28)$ & $4(28.57)$ & $73(25.35)$ & \\
\hline \multicolumn{6}{|l|}{$\mathrm{HL}$} \\
\hline No & $149(85.14)$ & $82(82.83)$ & $13(92.86)$ & 244 (84.72) & 0.724 \\
\hline Yes & $26(14.86)$ & $17(17.17)$ & I (7.14) & $44(15.28)$ & \\
\hline \multicolumn{6}{|l|}{ CAD } \\
\hline No & I52 (86.86) & $85(85.86)$ & $14(100)$ & $25 I(87.15)$ & 0.407 \\
\hline Yes & $23(13.14)$ & $14(14.14)$ & $0(0)$ & $37(12.85)$ & \\
\hline
\end{tabular}

Note: Fisher's exact test (Monte Carlo).

Abbreviations: CAD, coronary artery disease; DM, diabetes mellitus; HL, hyperlipidemia; HT, hypertension. 
Table 4 Carotid and vertebral artery stenosis and stenting results according to aortic arch types

\begin{tabular}{|c|c|c|c|c|c|}
\hline & \multicolumn{4}{|l|}{ Arch types } & \multirow[t]{2}{*}{$P$-value } \\
\hline & Type I, n (\%) & Type 2, n (\%) & Type 3, n (\%) & Total, n (\%) & \\
\hline \multicolumn{6}{|c|}{ Stent placement } \\
\hline No & I 38 (78.86) & 7I (7I.72) & II (78.57) & 220 (76.39) & 0.433 \\
\hline Yes & $37(21.14)$ & $28(28.28)$ & $3(2 \mathrm{I} .43)$ & $68(23.6 I)$ & \\
\hline \multicolumn{6}{|c|}{ RCS (\%) } \\
\hline$<50$ & I 57 (89.7I) & 79 (79.80) & $14(100)$ & $250(86.8 I)$ & 0.022 \\
\hline$\geq 50$ & $18(10.29)$ & $20(20.20)$ & $0(0)$ & 38 (13.19) & \\
\hline \multicolumn{6}{|l|}{ RCASP } \\
\hline No & I 45 (82.86) & 70 (70.7I) & $13(92.86)$ & $228(79.17)$ & 0.028 \\
\hline Yes & $30(17.14)$ & $29(29.29)$ & I (7.I4) & $60(20.83)$ & \\
\hline \multicolumn{6}{|c|}{ LCS (\%) } \\
\hline$<50$ & 145 (82.86) & 77 (77.78) & $13(92.86)$ & $235(81.60)$ & 0.368 \\
\hline$\geq 50$ & $30(17.14)$ & $22(22.22)$ & I (7.|4) & $53(18.40)$ & \\
\hline \multicolumn{6}{|l|}{ LCASP } \\
\hline No & I 35 (77.14) & $64(64.65)$ & II (78.57) & $210(72.92)$ & 0.078 \\
\hline Yes & $40(22.86)$ & 35 (35.35) & $3(21.43)$ & $78(27.08)$ & \\
\hline \multicolumn{6}{|c|}{ RVS (\%) } \\
\hline$<50$ & $163(93.14)$ & 93 (93.94) & I2 (85.7I) & $268(93.06)$ & 0.422 \\
\hline$\geq 50$ & $12(6.86)$ & $6(6.06)$ & $2(14.29)$ & $20(6.94)$ & \\
\hline \multicolumn{6}{|l|}{ RVASP } \\
\hline No & I54 (88) & 87 (87.88) & I2 (85.7I) & $253(87.85)$ & 0.906 \\
\hline Yes & $2 I(12)$ & $12(12.12)$ & $2(14.29)$ & $35(12.15)$ & \\
\hline \multicolumn{6}{|l|}{ LVS (\%) } \\
\hline$<50$ & $168(96)$ & 94 (94.95) & $13(92.86)$ & 275 (95.49) & 0.599 \\
\hline$\geq 50$ & $7(4)$ & $5(5.05)$ & I (7.14) & $13(4.5 \mid)$ & \\
\hline \multicolumn{6}{|l|}{ LVASP } \\
\hline No & $159(90.86)$ & 89 (89.90) & II (78.57) & 259 (89.93) & 0.292 \\
\hline Yes & $16(9.14)$ & $10(10.10)$ & $3(21.43)$ & $29(10.07)$ & \\
\hline
\end{tabular}

Note: Fisher's exact test (Monte Carlo).

Abbreviations: LCASP, left carotid artery stent placement; LCS, left carotid artery stenosis; LVASP, left vertebral artery stent placement; LVS, left vertebral artery stenosis; RCASP, right carotid artery stent placement; RCS, right carotid artery stenosis; RVAS, right vertebral artery stenosis; RVASP, right vertebral artery stent placement.

\section{Discussion}

The diversity of the aortic arch between patients leads to atheromatous plaque formation through different pathophysiological mechanisms and to differences in stroke incidence. This difference is very important for the survival of patients and the choice of treatment methods used. In many studies conducted with postmortem research and transesophageal echocardiography, the presence of aortic arch-located atherosclerotic lesions has been detected in a large proportion of patients with stroke of undetermined etiology.$^{9-11}$ In a broad participation study, lesions located in the aortic arch that are $\geq 4 \mathrm{~mm}$ have been shown to be closely related to recurrent cerebral infarct and other major cardiovascular events. ${ }^{12}$ The association of congenital aortic arch variations with the risk of cerebrovascular disease and serious disability has not yet been clearly defined.

In the current study, patients with Type 2 aortic arch with cerebrovascular disease were determined to have a higher likelihood of stenosis in the right carotid artery, requiring stenting.
However, there was no significant difference in terms of stent requirements between aortic arch types.

The direct relationship of aortic arch differences with stroke is controversial. Many cases of perioperative ischemia and infarcts due to these differences have been previously reported. ${ }^{13}$ Madhwal et al ${ }^{1}$ developed an aortic arch identification format with which important results were obtained in a systematic approach to aortic intervention.

Although the structural features and branching pattern of the aortic arch are usually congenital, they may change with age due to aortic elongation and environmental factors. ${ }^{14}$ These changes have been seen to increase in Type 3 aortic arch incidence particularly in patients older than 70 years. ${ }^{16}$ Lin et $\mathrm{al}^{17}$ demonstrated that this difference did not exist in patients younger than 80 years. As the mean age of the patients in the current study was 58 years, aortic elongation due to aging and common atherosclerotic lesions were seen less and, therefore, more accurate localization of the lesions responsible for the stroke could be applied. 
In stroke patients with Type 3 aortic arch, cerebral ischemia is increased during the procedure as the angiographic procedure is more complex and more prolonged. Bernardi and Dettor ${ }^{18}{ }^{18}$ indicated that vessels originating from an aortic arch of large and abnormal localization may have different effects on the cerebral circulation due to different hemodynamic characteristics. The average age of the patients in the study was 58.25 years, which was similar to ages reported in similar studies. Remarkably, the average age of patients with Type 3 aortic arches was 65.1 years, which is especially significant in this regard, although this age difference was not statistically significant $(P>0.05)$ (Table 1$)$. These findings are thought to be related to the low number of patients in this study.

DSA imaging, which is used to describe the aortic structural features, yields very successful results and is of great benefit to clinicians. In the current study, $60.7 \%$ of the patients evaluated with DSA imaging were found to have a normal aortic arch and this rate was lower than expected. This can be explained by the low number of patients in the study and the high detection rates of patients with Type 2 aortic arch and bovine arch. The Type 3 aortic arch rate was determined as $4.8 \%$ and is compatible with the literature. ${ }^{19}$

Differences in aortic arch structure and its branching, which are particular congenital features, may cause some difficulties in surgical and interventional radiological procedures that affect the diagnosis, treatment, and outcome of cerebrovascular diseases. ${ }^{20}$ The incidence of the bovine arch is known to be the most common anatomic variation of the aorta, with an incidence ranging from $8 \%$ to $30 \%$ in many studies. ${ }^{8,21,22}$ Despite the increased endovascular intervention options and experience, technical difficulties in the presence of bovine arch still remain significant. In some studies, it has been suggested that carotid stenting in patients with aortic arch anomalies should be applied to patient groups with a low chance of surgery. ${ }^{15}$ In the current study, the aortic bovine arch incidence was found to be $17.36 \%$, which was consistent with most demographic studies in literature and there was no difference in stenosis incidence and stenting frequency in arterial branches $(P>0.05)$ (Table 2)..$^{13,23}$

Aortic branching differences have been shown to be associated with increased neurological complications following carotid artery stent placement (CASP). ${ }^{1,15}$ In one study, it was shown that the most frequent cause of failure during CASP was due to differences in aortic arch tortuosity and angulation. ${ }^{17}$ It has been reported that the incidence of these anatomic difficulties increases in old age and there is also an increase in CASP complications secondary to the increase of vessel elongation over time. ${ }^{14,17}$ According to Bernardi and Dettori, ${ }^{18}$ the presence of abnormally positioned vertebral arteries can cause cerebral diseases by creating a difference in cerebral hemodynamics.

\section{Conclusion}

The results of this study determined that the aortic arch and its branching had no direct effect on the risk of cerebrovascular disease or stenting rates (which is the reason for the recent use of new operating catheters, long sheaths, hydrophilic and Teflon guide wires, and so on). This study can be considered of value in raising awareness for new studies to be conducted to demonstrate the effect of aortic arch anatomic differences on cerebrovascular diseases.

\section{Acknowledgment}

No financial support was received from any institution or foundation in this study.

\section{Author contributions}

All authors contributed toward data analysis, drafting and critically revising the paper and agree to be accountable for all aspects of the work.

\section{Disclosure}

The authors report no conflicts of interest in this work.

\section{References}

1. Madhwal S, Rajagopal V, Bhatt DL, Bajzer CT, Whitlow P, Kapadia SR. Predictors of difficult carotid stenting as determined by aortic arch angiography. J Invasive Cardiol. 2008;20(5):200-204.

2. Timsit SG, Sacco RL, Mohr JP, et al. Early clinical differentiation of cerebral infarction from severe atherosclerotic stenosis and cardioembolism. Stroke. 1992;23(4):486-491.

3. Faries PL, Chaer RA, Patel S, Lin SC, DeRubertis B, Kent KC. Current management of extracranial carotid artery disease. Vasc Endovascular Surg. 2006;40(3):165-175.

4. Rekha P, Senthilkumar S. A study on branching pattern of human aortic arch and its variations in south indian population. J Morphol Sci. 2013;30(1):11-15.

5. Chernin MM, Pond GD, Sahn DJ. Digital subtraction angiography of the aortic arch. Cardiovasc Intervent Radiol. 1984;7(5):196-203.

6. Moodie DS, Yiannikas J, Gill CC, Buonocore E, Pavlicek W. Intravenous digital subtraction angiography in the evaluation of congenital abnormalities of the aorta and aortic arch. Am Heart J. 1982;104(3):628-634.

7. Lippert H, Pabst R. Aortic Arch in Arterial Variations in Man Classification and Frequency. Munich: JF Bergmann-Verlag; 1985:3-10.

8. Spacek M, Veselka J. Bovine arch. Arch Med Sci. 2012;8(1): 166-167.

9. Karalis DG, Chandrasekaran K, Victor MF, Ross JJJ, Mintz GS. Recognition and embolic potential of intraaortic atherosclerotic debris. J Am Coll Cardiol. 1991;17(1):73-78.

10. Amarenco P, Duyckaerts C, Tzourio C, Henin D, Bousser MG, Hauw JJ. The prevalence of ulcerated plaques in the aortic arch in patients with stroke. N Engl J Med. 1992;326(4):221-225. 
11. Katz ES, Tunick PA, Rusinek H, Ribakove G, Spencer FC, Kronzon I. Protruding aortic atheromas predict stroke in elderly patients undergoing cardiopulmonary bypass: experience with intraoperative transesophageal echocardiography. J Am Coll Cardiol. 1992;20(1): 70-77.

12. French Study of Aortic Plaques in Stroke Group; Amarenco P, Cohen A, et al. Atherosclerotic disease of the aortic arch as a risk factor for recurrent ischemic stroke. N Engl J Med. 1996;334(19):1216-1221.

13. Burzotta F, Nerla R, Pirozzolo G, et al. Clinical and procedural impact of aortic arch anatomic variants in carotid stenting procedures. Catheter Cardiovasc Interv. 2015;86(3):480-489.

14. Hobson RW 2nd, Howard VJ, Roubin GS, et al. Carotid artery stenting is associated with increased complications in octogenarians: 30-day stroke and death rates in the CREST lead-in phase. J Vasc Surg. 2004 40(6):1106-1111.

15. Faggioli GL, Ferri M, Freyrie A, et al. Aortic arch anomalies are associated with increased risk of neurological events in carotid stent procedures. Eur J Vasc Endovasc Surg. 2007;33(4):436-441.

16. Kojima A, Saga I. Effect of aging on the configurational change of the aortic arch. Geriatr Care. 2016;2(1):20-22.
17. Lin SC, Trocciola SM, Rhee J, et al. Analysis of anatomic factors and age in patients undergoing carotid angioplasty and stenting. Ann Vasc Surg. 2005;19(6):798-804.

18. Bernardi L, Dettori P. Angiographic study of a rare anomalous origin of the vertebral artery. Neuroradiology. 1975;9(1):43-47.

19. Natsis KI, Tsitouridis IA, Didagelos MV, Fillipidis AA, Vlasis KG, Tsikaras PD. Anatomical variations in the branches of the human aortic arch in 633 angiographies: clinical significance and literature review. Surg Radiol Anat. 2009;31(5):319-323.

20. Nayak SR, Pai MM, Prabhu LV, D’Costa S, Shetty P. Anatomical organization of aortic arch variations in the India: embryological basis and review. J Vasc Bras. 2006;5(2):95-100.

21. Demertzis S, Hurni S, Stalder M, Gahl B, Herrmann G, Van Den Berg J. Aortic arch morphometry in living humans. J Anat. 2010;217(5) 588-596.

22. Tapia GP, Zhu X, Xu J, et al. Incidence of branching patterns variations of the arch in aortic dissection in Chinese patients. Medicine (Baltimore). 2015;94(17):e795.

23. Shaw JA, Gravereaux EC, Eisenhauer AC. Carotid stenting in the bovine arch. Catheter Cardiovasc Interv. 2003;60(4):566-569.
Neuropsychiatric Disease and Treatment

\section{Publish your work in this journal}

Neuropsychiatric Disease and Treatment is an international, peerreviewed journal of clinical therapeutics and pharmacology focusing on concise rapid reporting of clinical or pre-clinical studies on a range of neuropsychiatric and neurological disorders. This journal is indexed on PubMed Central, the 'PsycINFO' database and CAS,

\section{Dovepress}

and is the official journal of The International Neuropsychiatric Association (INA). The manuscript management system is completely online and includes a very quick and fair peer-review system, which is all easy to use. Visit http://www.dovepress.com/testimonials.php to read real quotes from published authors. 